\title{
Promotion of Chondrosarcoma Cell Survival, Migration and Lymphangiogenesis by Periostin
}

\author{
JI YUN JEONG ${ }^{1}$, WONJU JEONG ${ }^{2}$ and HA-JEONG $\mathrm{KIM}^{3,4}$ \\ ${ }^{1}$ Department of Pathology, Kyungpook National University, School of Medicine, Daegu, Republic of Korea; \\ ${ }^{2}$ Department of Orthopedic Surgery, Kyungpook National University, School of Medicine, Daegu, Republic of Korea; \\ ${ }^{3}$ Department of Physiology, Kyungpook National University, School of Medicine, Daegu, Republic of Korea; \\ ${ }^{4}$ BK21 Plus KNU Biomedical Convergence Program, Department of Biomedical Science, \\ Kyungpook National University, School of Medicine, Daegu, Republic of Korea
}

\begin{abstract}
Background/Aim: Periostin exists as an extracellular matrix protein in several carcinomas and is related to metastasis and poor prognosis. It is mainly secreted from cancer associated fibroblasts, and not from carcinoma cells. As a tumor microenvironment component, periostin usually mediates tumor cell stemness, metastasis, angiogenesis and lymphangiogenesis. This study aimed to examine the role of periostin in chondrosarcoma. Materials and Methods: To evaluate the effect of periostin on the proliferation of chondrosarcoma cells, MTT assay was performed on SW1353 cells and periostin knockdown SW1353 cells. Migration activity was examined using Boyden chamber. Results: Periostin, secreted from chondrosarcoma cells, was found to support proliferation, and maintain stemness and migration of chondrosarcoma cells. Periostin also induced proliferation and migration of lymphatic endothelial cells. Conclusion: Periostin plays an important role in chondrosarcoma development and disease progression.
\end{abstract}

Chondrosarcoma is the second most common bone tumor. Because it usually grows slowly and rarely metastasizes, its clinical outcome is generally not serious if adequate surgery is performed. However, patient's inconvenience is usually due to an excessive excision (1). It is difficult to distinguish between benign enchondroma and malignant low-grade chondrosarcoma. Radiological findings and clinical information are used to distinguish them, because the histological difference is not clear $(2,3)$. A lot of molecules

This article is freely accessible online.

Correspondence to: Ha-Jeong Kim, 680 Gukchaebosang-ro, Junggu, Daegu 41944, Republic of Korea. Tel: +82 534204811, Fax: +82 534243349, e-mail: kimhajeong@knu.ac.kr

Key Words: Periostin, carcinoma, stemness, metastasis, angiogenesis, lymphangiogenesis, chondrosarcoma. have been reported to be involved in the disease progression such as tumorigenesis, metastasis, angiogenesis, and lymphangiogenesis (2). However, there is no effective treatment, because pathological tumorigenesis mechanism of chondrosarcoma is still not clear.

Tumor tissue is not only composed of tumor cells, but also other cells, including immune cells, blood endothelial cells, lymphatic endothelial cells, and fibroblasts. It is well known that the tumor microenvironment is significantly involved in tumor progression. The tumor microenvironment contributes to the maintenance of cancer stemness, and promotion of invasion, metastasis, angiogenesis, and lymphangiogenesis (4). Cancer-associated fibroblasts (CAFs) are the most abundant cell type in the tumor except from tumor cells. CAFs affect the growth and maintenance of cancers by several secreting factors (5). Gene expression profiling of CAFs is different from that of normal fibroblasts in the tissue. Fibroblastspecific protein (FSP-1), also known as S100A4, the fibroblast-activating protein (FAP), vimentin, and alphasmooth muscle actin (a-SMA) are the typical products of CAFs $(6,7)$. Extracellular matrix proteins, also components of the tumor microenvironment, are mainly secreted by CAFs, and also support cancer progression by affecting tumor cells, tumor infiltrating immune cells, blood endothelial cells and lymphatic endothelial cells (8). Periostin is also secreted from CAFs, and is frequently overexpressed in various tumors such as a breast, lung, head and neck and colon cancer (9-12).

Periostin is a $90 \mathrm{kDa}$ extracellular matrix protein composed of an Emilin-like (EMI) domain and 4 repeated and conserved fasciclin 1 (FAS1) domains. Integrins $\alpha v \beta 3$ and $\alpha v \beta 5$, and DDR1 have been reported as its receptors $(13,14)$. It exists normally in periosteum and mediates bone formation (15), and is often associated with inflammation and fibrosis in adult tissues (16-18). However, it is abundantly expressed in the tumor microenvironment. The role of periostin in carcinoma development is well reported. Periostin exists in the lung premetastatic niche (19) and increased serum periostin is found in 
A

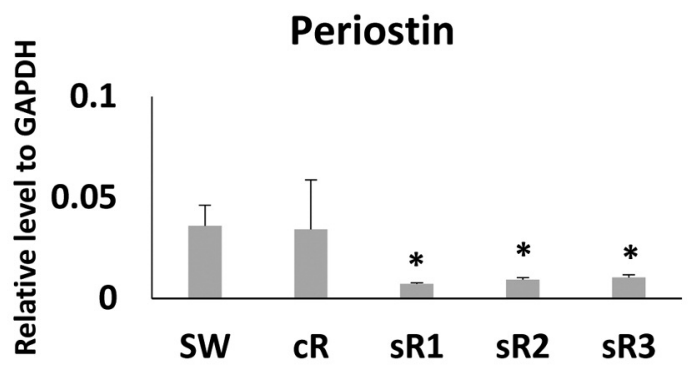

C

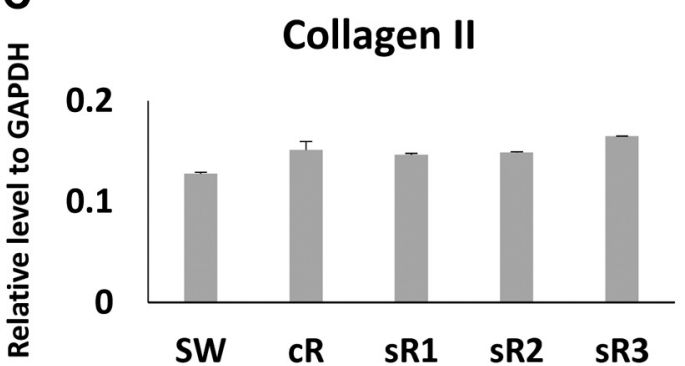

B

SW CR SR1 SR2 sR3

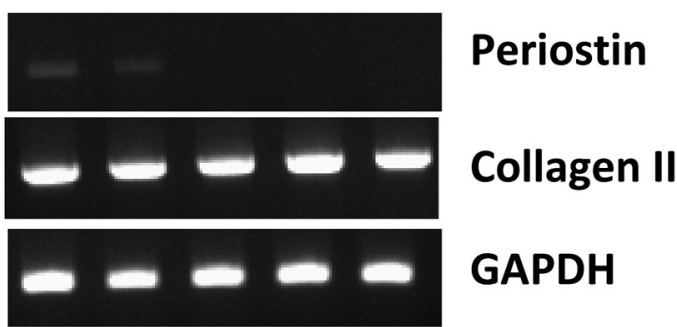

D $\begin{array}{llll}C R & S R 1 & S R 2 & S R 3\end{array}$

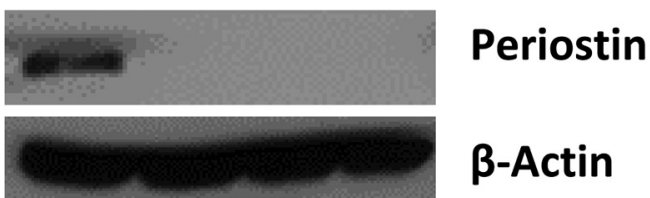

Figure 1. Periostin and collagen II expression in chondrosarcoma cells. Three different periostin siRNAs (sR1, sR2, and sR3) and control siRNA (cR) were transiently transfected to SW1353 cells. Total RNA was extracted, and cDNA were synthesized. (A) Quantitative real time PCR was performed with periostin primers in SW1353 chondrosarcoma cells (SW, and cR) and periostin knockdown SW1353 cells (sR1, sR2, and sR3). Data are presented as mean \pm SD from three individual experiments. ${ }^{*} p<0.05$ compared with the $c R$ group. (B) Reverse transcriptase PCR was performed with periostin primers and collagen II primers in SW1353 chondrosarcoma cells (SW, and cR) and periostin knockdown SW1353 cells (sR1, sR2, and sR3). Data are presented one result among three different independent experiments. (C) Quantitative real time PCR was performed with collagen II primers in SW1353 chondrosarcoma cells (SW, and $c R$ ) and periostin knockdown SW1353 cells (sR1, sR2, and sR3). Data are presented as mean \pm SD from three individual experiments. (D) Periostin protein expression. Immunoblot assay was performed with anti-periostin antibody and anti-b-actin antibody in SW1353 chondrosarcoma cells (SW, and $c R)$ and periostin knockdown SW1353 cells (sR1, sR2, and sR3). Data are representative of three different independent experiments.

human breast cancer patients with bone metastases $(20,21)$. It also supports cancer cell stemness, especially via Wnt signaling $(19,22)$. As an extracellular matrix protein, periostin also induces angiogenesis and lymphangiogenesis $(9,23)$. It is also expressed in chondrosarcoma and its expression differs according to the clinical stage of chondrosarcoma (24). This study aimed to examine the role of periostin in chondrosarcoma.

\section{Materials and Methods}

Cell culture. The SW1353 human chondrosarcoma cell line was obtained from American Type Culture Collection and human lymphatic endothelial cells were obtained from Lonza (Walkersville, MD, USA). Each cell line was maintained according to the manufacturer's protocol. For the generation of periostin knockdown cells, periostin siRNA obtained from Thermo Fisher Scientific (Waltham, MA, USA) was used. Control siRNA was also obtained from Thermo Fisher Scientific. Cells were transiently transfected with control or periostin siRNA using Lipofectamine 3000 (Invitrogen, MA, USA). A total of $10^{6}$ cells were plated with $10 \mathrm{ml}$ of $5 \%$ FBS DMEM media and incubated for $72 \mathrm{~h}$ in $37^{\circ} \mathrm{C}$. Conditioned media (CM) were collected and cell particles were removed using centrifugation.
Reverse-transcription polymerase chain reaction (RT-PCR) and quantitative real time PCR. Total cellular RNA was isolated using the RNA extraction kit (Takara Bio, Otsu, Japan). cDNA was synthesized from $1 \mu \mathrm{g}$ total RNA using a cDNA synthesis kit (Takara Bio) according to the manufacturer's instructions. The primer pair sequences used were: human periostin, 5'- AACCAAGGACCTGAAACACG-3' and 5'GTGTCAGGACACGGTCAATG-3'; human collagen II 5'CGTCCAGATGACCTTCCTACG-3' and 5'-TGAGCAGGGCCTT CTTGAG-3'; human GAPDH, 5'- TCACCACCATGGAGAAGGC-3' and 5'-GCTAAGCAGTTGGTGGTGCA-3'. Total cDNA was amplified using Go Taq ${ }^{\circledR}$ Green Master Mix (Promega, Madison, WI, USA) for 25-30 cycles of denaturation at $94^{\circ} \mathrm{C}$ for $20 \mathrm{~s}$, annealing at $60^{\circ} \mathrm{C}$ for 30 $\mathrm{s}$, and extension at $72^{\circ} \mathrm{C}$ for $1 \mathrm{~min}$ (for all primers). The products were resolved on $1.5 \%$ agarose-TAE gels at $100 \mathrm{mV}$ and visualized by ethidium bromide staining. Quantitative real-time PCR was performed using SYBR Premix Ex Taq from Takara Bio. Data are presented as fold changes in mRNA expression relative to GAPDH expression.

Western blot analysis. Cell lysates were obtained using a cell lysis buffer from Cell Signaling Technology (MA, USA) by following the manufacturer's instructions. Protein concentration of cell lysates was measured using Bradford protein assay (Bio-Rad, CA, USA), and a total of $20 \mu \mathrm{g}$ protein were loaded on a well of an SDSpolyacrylamide gel. Gel separated proteins were transferred to the 
nitrocellulose membrane. Anti-periostin antibody (Cell Signaling Technology) and anti- $\beta$-actin monoclonal antibody (Sigma, St. Louis, MO, USA) were used.

MTT proliferation assay. The tetrazolium 3-(4, 5-dimethylthiazolyl-2)2,5-diphenyltetrazolium bromide (MTT) buffer was obtained from Sigma. $5 \times 10^{4} /$ well cells were plated on 96 well plates and incubated under the indicated experimental conditions. Ten $\mu \mathrm{l}$ of MTT buffer was added and incubated for $2 \mathrm{~h}$ at $37^{\circ} \mathrm{C}$. One hundred $\mu \mathrm{l}$ of dimethyl sulfoxide (DMSO) solution was added and incubated for $10 \mathrm{~min}$ at room temperature in the dark. Absorbances were read at $550 \mathrm{~nm}$.

Migration assay. Cells were seeded into the upper chamber of Transwell $(8-\mu \mathrm{m}$ pore size; Corning, Costar) in 24-well plates at a density of $5 \times 10^{4}$ cells per well. Recombinant periostin, conditioned media obtained from SW1353 cells, and/or recombinant VEGF-C (R\&D system) were added in the lower chamber. After incubation for the indicated time periods, cells migrated through the Transwell membrane were fixed, stained with crystal violet, and then measured using MacBiophotonics Image $\mathbf{J}$ software.

Statistical analysis. The results are presented as mean \pm S.D. from at least three independent experiments. All the statistical analyses were performed with paired $t$-test. Data were considered significant if $p<0.05$.

\section{Results}

Generation of periostin knockdown chondrosarcoma cells. Periostin expression was confirmed in SW1353 human chondrosarcoma cells. Periostin mRNA expression in SW1353 cells was detected by q-PCR and RT-PCR (Figure 1A and B). Periostin knockdown cells were also generated by transfection with periostin siRNA. Periostin mRNA levels were decreased following transfection with the periostin siRNA, but not those of collagen II mRNA (Figure 1B and C).

Periostin supports proliferation of chondrosarcoma cells and maintenance of stemness. To evaluate the effect of periostin on the proliferation of chondrosarcoma cells, MTT assay was performed on SW1353 cells and periostin knockdown SW1353 cells. Proliferation of SW1353 cells decreased when periostin levels were decreased (siR1, siR2, and siR3 in Figure 2A). Treatment of cells with recombinant periostin did not induce SW1353 cell proliferation. However, the decreased proliferation of periostin knockdown SW1353 cells was restored by the addition of recombinant periostin (Figure 2B).

Sex-determining region $\mathrm{Y}$ (SRY)-related high mobility group-BOX gene 4 (SOX4) and SOX9 are involved in chondrogenesis and are increased in chondrosarcoma (2527). SOX4 and SOX9 mRNA expression in SW1353 cells and periostin knockdown SW1353 cells. As shown in Figure 2C, SOX4 and SOX9 mRNA expression was reduced in periostin knockdown SW1353 cells. Recombinant periostin itself did not increase SOX4 and SOX9 mRNA expression but restored the decreased proliferation of periostin knockdown SW1353 cells (Figure 2C).

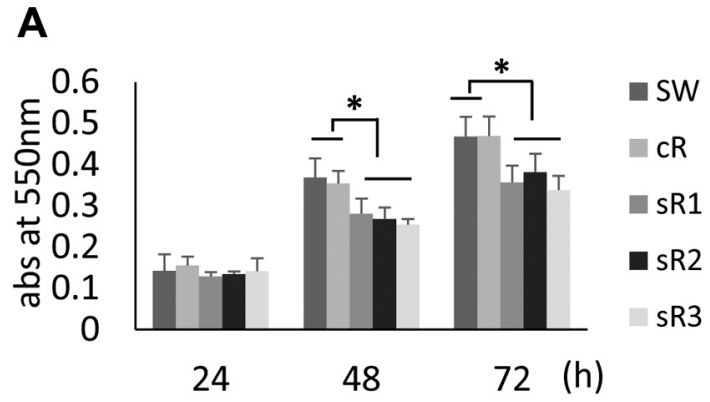

B

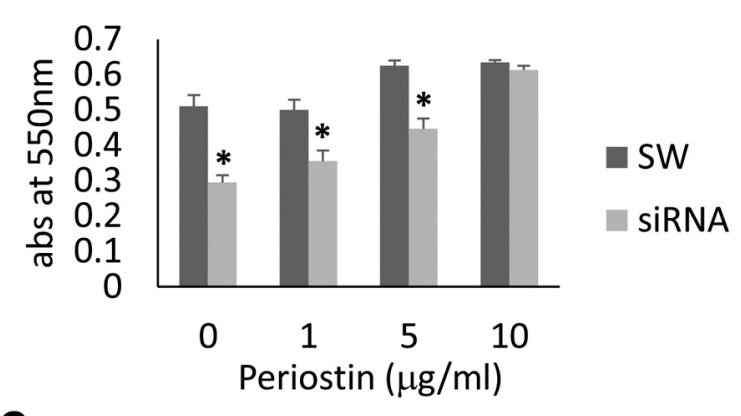

C

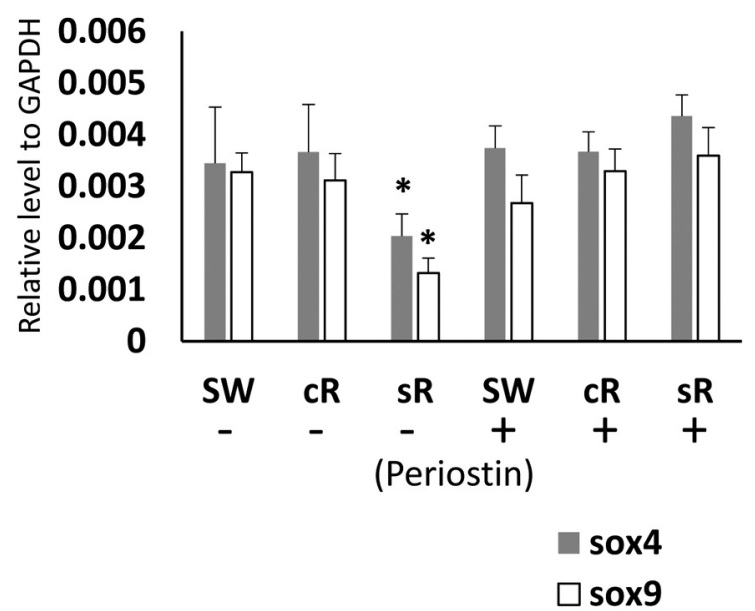

Figure 2. Periostin promotes chondrosarcoma cell proliferation. (A) $M T T$ assay. Three different periostin siRNA (sR1, sR2, and $s R 3)$ and control siRNA (cR) were transiently transfected to SW1353 cells. Cells were plated on microplates and incubated for the indicated times. MTT assay was performed as described in Materials and Methods. Data are presented as mean $\pm S D$ from three independent experiments. $* p<0.05$ (B) MTT assay. Cells were plated on microplates and $10 \mu \mathrm{g}$ of recombinant periostin was added at the indicated concentrations for 72 h. MTT assay was performed. Data are presented as mean $\pm S D$ from three independent experiments. ${ }^{*} p<0.05$ compared with the $S W$ group. (C) SOX4 and SOX9 mRNA expression. Cells were incubated with or without $10 \mu \mathrm{g}$ of periostin for $72 \mathrm{~h}$. Total RNA were extracted and cDNA were synthesized. Quantitative real time PCR was performed with SOX4 and SOX9 primers in SW1353 chondrosarcoma cells (SW, and $c R$ ) and periostin knockdown $S W 1353$ cells (sR). Data are presented as mean $\pm S D$ from three independent experiments. $* p<0.05$ compared with the $c R$ group. 
A

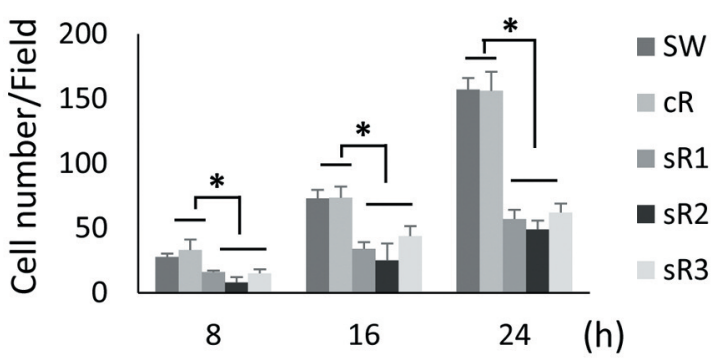

B

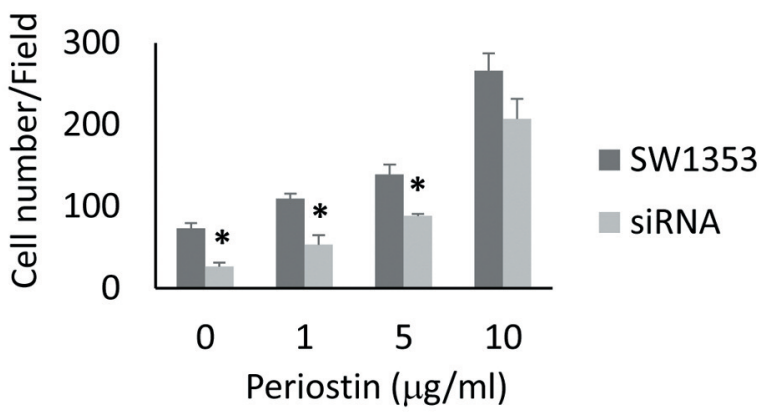

C

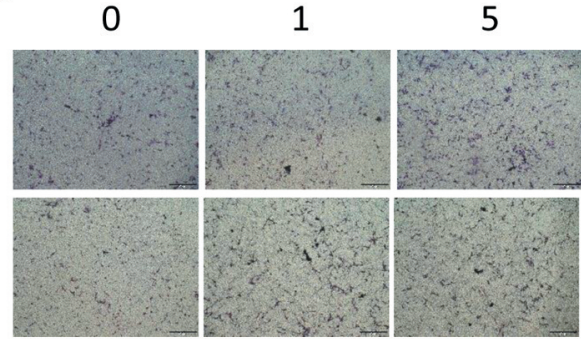

10 Periostin $(\mu \mathrm{g} / \mathrm{ml})$

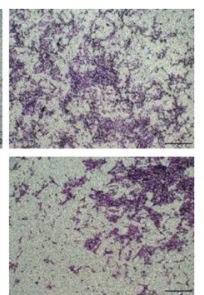

SW1353

SiRNA

Figure 3. Periostin promotes chondrosarcoma cell migration. Three different periostin siRNA (sR1, sR2, and sR3) and control siRNA (cR) were transiently transfected into SW1353 cells. (A) Migration assay. Cells were plated on the upper chamber and incubated for the indicated times. After removal of unmigrated cells on upper chamber, migrated cells were fixed and stained with crystal violet. Cell number in high-power field was counted and presented. Data are presented as mean $\pm S D$ from three independent experiments. ${ }^{*} p<0.05(B)$ Migration assay. Cells were plated on upper chamber with or without the indicated concentration of recombinant periostin. The cell number in high-power field was counted and presented. Data are presented as mean $\pm S D$ from three independent experiments. * $p<0.05$ compared with SW1353 cells. (C) Microscopic images. Scale bar: 200 mm.

Periostin mediates chondrosarcoma cell migration. Migration activity was examined using Boyden chamber. SW1353 cells or periostin knockdown SW1353 cells were plated on the upper well, and migrated cells were counted at the indicated times. Migration of periostin knockdown SW1353 cells was less than that of SW1353 cells (Figure $3 \mathrm{~A})$. When recombinant periostin was added, the migration of SW1353 cells increased in a dose-dependent manner. Reduced migration of periostin knockdown SW1353 cells was recovered by recombinant periostin (Figure $3 \mathrm{~B}$ and C).

Promotion of the proliferation and migration of lymphatic endothelial cells by chondrosarcoma secreted periostin. To determine the effect of periostin on lymphatic endothelial cells, conditioned media (CM) collected from SW1353 cells and periostin knockdown SE1353 cells were used. CM were prepared as described in the Materials and Methods section. Lymphatic endothelial cells were plated and maintained with $20 \%$ of the indicated CM and $80 \%$ fresh media. The proliferation was examined by the MTT assay. The proliferation of lymphatic endothelial cells increased in the presence of SW1353 CM compared to fresh media only. CM from periostin deficient SW1353 cells did not induce the proliferation of lymphatic endothelial cells (Figure 4A). Recombinant periostin supported the proliferation of lymphatic endothelial cells in a dose-dependent manner and restored the decreased effect of periostin deficient $\mathrm{CM}$ (Figure 4B).

The effects on lymphatic endothelial cells migration were also examined. Lymphatic endothelial cells were seeded on the upper wells of the Boyden chamber, and the indicated $\mathrm{CM}$ with VEGF-C were added to the lower wells. Migrated cells were stained and counted on a high-power field of a microscope. VEGF-C itself induced lymphatic endothelial cells migration, and CM from SW1353 increased the VEGF$\mathrm{C}$-induced lymphatic endothelial cell migration. Periostin deficient CM lost this increase (Figure 4C). Recombinant periostin promoted lymphatic endothelial cell migration in a dose-dependent manner (Figure 4D).

\section{Discussion}

Sarcomas and carcinomas are types of malignant tumors. Tumor cells in carcinomas derive from tumorigenic changes of epithelial cells, but tumor cells in sarcomas derive from mesenchymal cells. Sarcomas are much less 

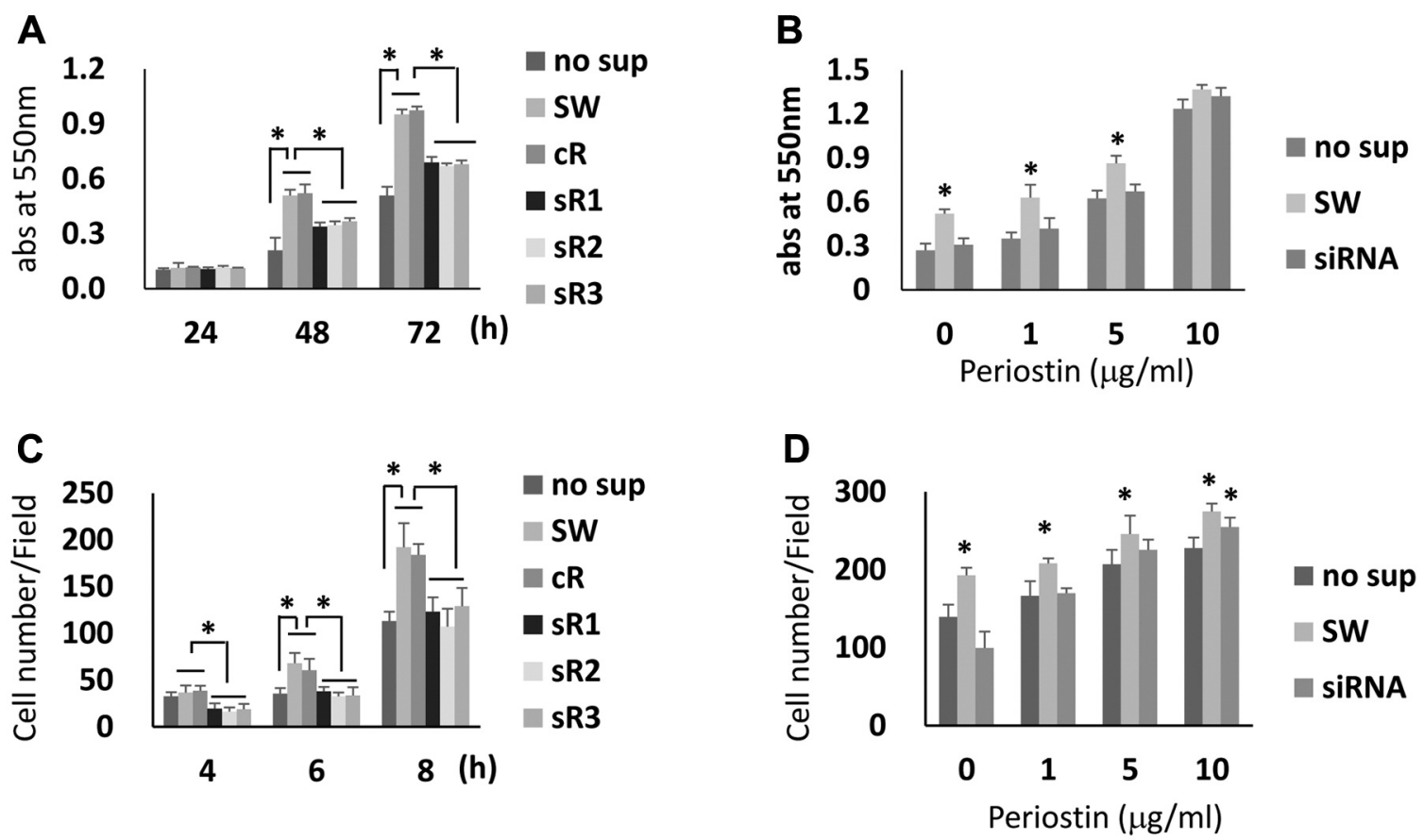

Figure 4. Periostin from chondrosarcoma cells promotes the lymphatic endothelial cell proliferation and migration. Three different periostin siRNA $(s R 1, s R 2$, and $s R 3)$ and control siRNA (cR) were transiently transfected to SW1353 cells. Conditioned media (CM) were collected from the indicated cells. (A and B) MTT assay. Lymphatic endothelial cells and CM with or without recombinant periostin were incubated for the indicated times. Data are presented as mean $\pm S D$ from three individual experiments. ${ }^{*} p<0.05$ (C and D) Migration assay. Lymphatic endothelial cells were plated on the upper well. CM and VEGF-C with or without recombinant periostin were added in the lower chamber. After removal of the unmigrated cells on the upper chamber, migrated cells were fixed and stained with crystal violet. The cell number in high-power field was counted and presented. Data are presented as mean $\pm S D$ from three independent experiments. ${ }^{*} p<0.05$.

common than carcinomas, and studies about the tumorigenic changes in sarcomas are also limited (28). Both tumor tissues are composed of tumor cells and various other cells types, including immune cells, blood endothelial cells, lymphatic endothelial cells, fibroblasts and others. These different cells comprise the tumor microenvironment, which affects tumor progression through contact with tumor cells (4). Most of these studies were performed on carcinomas. In sarcoma, both tumor cells and tumor microenvironment derive from mesenchymal stem cells; thus, it is difficult to distinguish between tumor cells and other cell types, especially CAFs (29).

Chondrosarcomas are formed by malignant changes in chondrocytes, which derive from mesoderm $(1,30,31)$. Periostin is abundant in the stroma of several carcinomas, and is secreted from CAFs, and not tumor cells (22). CAFs are not common in chondrosarcoma, but periostin expression has been reported (24). Periostin is observed in the cytoplasm but not in the extracellular matrix of enchondroma tissue, and is present in the cytoplasm and extracellular matrix of low-grade chondrosarcoma (unpublished data). In this report, periostin mRNA and protein expression in
SW1353 chondrosarcoma cells was confirmed (Figure 1). It is possible that periostin expression in sarcomas and carcinomas may be the result of dedifferentiation of mesenchymal stem cells. To confirm this hypothesis, more studies on other sarcomas are needed.

In periostin knockdown SW1353 cells, collagen II expression was not changed, but $\mathrm{SOX} 4$ and $\mathrm{SOX} 9$ expression was reduced (Figures $1 \mathrm{~B}, \mathrm{C}$ and $2 \mathrm{C}$ ). Proliferation also decreased in periostin knockdown SW1353 cells. SOX4 and SOX9 expression has been shown to increase in chondrosarcoma and related poor prognosis (25-27). These results suggest that periostin may regulate SOX4 and SOX 9 expression. Further studies are needed to clarify the molecular mechanism. It may be related to the role of periostin in maintaining tumor cell stemness (32).

Integrin $\alpha v \beta 3$ and $\alpha v \beta 5$ are major receptors of periostin (33). Chondrocytes express several integrins including $\alpha v \beta 3$ and $\alpha v \beta 5$ (34). Thus, interaction between periostin and integrins on chondrosarcoma cells may play a major role in the survival and proliferation like as has also been found in other cells $(35,36)$. Proliferation is reduced in periostin knockdown SW1353 cells, and recombinant periostin restored 
the phenotype. However, recombinant periostin does not promote proliferation (Figure $2 \mathrm{~B}$ ). These results suggest that periostin is important for chondrosarcoma proliferation, but the enhancing effect is limited.

It was also shown that periostin promoted the migration of chondrosarcoma cells in a dose-dependent manner (Figure $3)$. This is in agreement with other studies $(37,38)$. It has also reported that periostin expression correlates with metastasis (19-21, 39). The relation between periostin expression and clinical outcome of chondrosarcoma has not been reported. Studies on this subject can lead to the identification of new biomarkers for chondrosarcoma.

Lymphatics are important for tumor growth and metastasis (40). Periostin has been shown to promote lymphangiogenesis $(23,41)$. In this report, it was shown that periostin from SW1353 chondrosarcoma cells induced the proliferation and the migration of lymphatic endothelial cells (Figure 4). This supports the possibility that periostin from chondrosarcoma cells promotes lymphagiogenesis in chondrosarcoma tumor.

In this report we showed that periostin is expressed in chondrosarcoma cells. Periostin from chondrosarcoma induced the proliferation and the migration of chondrosarcoma cells. If this is the sign of dedifferentiation or stemness of chondrosarcoma cells, then, periostin could be a novel biomarker of chondrosarcoma.

\section{Conflicts of Interest}

The Authors declare no conflicts of interest regarding this study.

\section{Authors' Contributions}

Ji Yun Jeong, Wonju Jeong: conception and design of the study; HaJeong Kim: performed all experiments, drafted the manuscript and figures.

\section{Acknowledgements}

This work was supported by the National Research Foundation of Korea (NRF) grant funded by the Korea government (2016R1C1B2009103) and by Biomedical Research Institute grant, Kyungpook National University Hospital (2014).

\section{References}

1 Gelderblom H, Hogendoorn PC, Dijkstra SD, van Rijswijk CS, Krol AD, Taminiau AH and Bovee JV: The clinical approach towards chondrosarcoma. Oncologist 13(3): 320-329, 2008. PMID: 18378543. DOI: 10.1634/theoncologist.2007-0237

2 Jeong W and Kim HJ: Biomarkers of chondrosarcoma. J Clin Pathol 71(7): 579-583, 2018. PMID: 29593061. DOI: 10.1136/jclinpath-2018-205071

3 Ferrer-Santacreu EM, Ortiz-Cruz EJ, Gonzalez-Lopez JM and Perez Fernandez E: Enchondroma versus low-grade chondrosarcoma in appendicular skeleton: Clinical and radiological criteria. J Oncol 2012: 437958, 2012. PMID: 22593766. DOI: 10.1155/2012/437958
4 Quail DF and Joyce JA: Microenvironmental regulation of tumor progression and metastasis. Nat Med 19(11): 1423-1437, 2013. PMID: 24202395. DOI: 10.1038/nm.3394

5 Augsten M: Cancer-associated fibroblasts as another polarized cell type of the tumor microenvironment. Front Oncol 4: 62, 2014. PMID: 24734219. DOI: 10.3389/fonc.2014.00062

6 Sugimoto H, Mundel TM, Kieran MW and Kalluri R: Identification of fibroblast heterogeneity in the tumor microenvironment. Cancer Biol Ther 5(12): 1640-1646, 2006. PMID: 17106243. DOI: $10.4161 / \mathrm{cbt} .5 .12 .3354$

7 Spaeth EL, Dembinski JL, Sasser AK, Watson K, Klopp A, Hall B, Andreeff M and Marini F: Mesenchymal stem cell transition to tumor-associated fibroblasts contributes to fibrovascular network expansion and tumor progression. PLoS One 4(4): e4992, 2009. PMID: 19352430. DOI: 10.1371/journal.pone.0004992

8 Denton AE, Roberts EW and Fearon DT: Stromal cells in the tumor microenvironment. Adv Exp Med Biol 1060: 99-114, 2018. PMID: 30155624. DOI: 10.1007/978-3-319-78127-3_6

9 Shao R, Bao S, Bai X, Blanchette C, Anderson RM, Dang T, Gishizky ML, Marks JR and Wang XF: Acquired expression of periostin by human breast cancers promotes tumor angiogenesis through up-regulation of vascular endothelial growth factor receptor 2 expression. Mol Cell Biol 24(9): 3992-4003, 2004. PMID: 15082792. DOI: 10.1128/mcb.24.9.3992-4003.2004

10 Sasaki H, Lo KM, Chen LB, Auclair D, Nakashima Y, Moriyama S, Fukai I, Tam C, Loda M and Fujii Y: Expression of periostin, homologous with an insect cell adhesion molecule, as a prognostic marker in non-small cell lung cancers. Jpn J Cancer Res 92(8): 869-873, 2001. PMID: 11509119. DOI: 10.1111/j.1349-7006.2001.tb01174.X

11 Kudo Y, Ogawa I, Kitajima S, Kitagawa M, Kawai H, Gaffney PM, Miyauchi M and Takata T: Periostin promotes invasion and anchorage-independent growth in the metastatic process of head and neck cancer. Cancer Res 66(14): 6928-6935, 2006. PMID: 16849536. DOI: 10.1158/0008-5472.CAN-05-4540

12 Bao S, Ouyang G, Bai X, Huang Z, Ma C, Liu M, Shao R, Anderson RM, Rich JN and Wang XF: Periostin potently promotes metastatic growth of colon cancer by augmenting cell survival via the akt/pkb pathway. Cancer Cell 5(4): 329-339, 2004. PMID: 15093540. DOI: 10.1016/s1535-6108(04)00081-9

13 Laury AM, Hilgarth R, Nusrat A and Wise SK: Periostin and receptor activator of nuclear factor kappa-b ligand expression in allergic fungal rhinosinusitis. Int Forum Allergy Rhinol 4(9): 716-724, 2014. PMID: 25060295. DOI: 10.1002/alr.21367

14 Alfieri C, Kavvadas P, Simonini P, Ikehata M, Dussaule JC, Chadjichristos CE, Rastaldi MP, Messa P and Chatziantoniou C: Discoidin domain receptor-1 and periostin: New players in chronic kidney disease. Nephrol Dial Transplant 30(12): 19651971, 2015. PMID: 25829327. DOI: 10.1093/ndt/gfv074

15 Merle B and Garnero P: The multiple facets of periostin in bone metabolism. Osteoporos Int 23(4): 1199-1212, 2012. PMID: 22310955. DOI: 10.1007/s00198-011-1892-7

16 Masuoka M, Shiraishi H, Ohta S, Suzuki S, Arima K, Aoki S, Toda S, Inagaki N, Kurihara Y, Hayashida S, Takeuchi S, Koike K, Ono J, Noshiro H, Furue M, Conway SJ, Narisawa Y and Izuhara K: Periostin promotes chronic allergic inflammation in response to th2 cytokines. J Clin Invest 122(7): 2590-2600, 2012. PMID: 22684102. DOI: 10.1172/JCI58978

17 Sidhu SS, Yuan S, Innes AL, Kerr S, Woodruff PG, Hou L, Muller SJ and Fahy JV: Roles of epithelial cell-derived periostin 
in tgf-beta activation, collagen production, and collagen gel elasticity in asthma. Proc Natl Acad Sci U S A 107(32): 1417014175, 2010. PMID: 20660732. DOI: 10.1073/pnas.1009426107

18 Uchida M, Shiraishi H, Ohta S, Arima K, Taniguchi K, Suzuki S, Okamoto M, Ahlfeld SK, Ohshima K, Kato S, Toda S, Sagara H, Aizawa H, Hoshino T, Conway SJ, Hayashi S and Izuhara K: Periostin, a matricellular protein, plays a role in the induction of chemokines in pulmonary fibrosis. Am J Respir Cell Mol Biol 46(5): 677-686, 2012. PMID: 22246863. DOI: $10.1165 / \mathrm{rcmb} .2011-$ $0115 \mathrm{OC}$

19 Malanchi I, Santamaria-Martinez A, Susanto E, Peng H, Lehr HA, Delaloye JF and Huelsken J: Interactions between cancer stem cells and their niche govern metastatic colonization. Nature 481(7379): 85-89, 2011. PMID: 20715172. DOI: 10.1002/ijc.25591

20 Contie S, Voorzanger-Rousselot N, Litvin J, Clezardin P and Garnero P: Increased expression and serum levels of the stromal cell-secreted protein periostin in breast cancer bone metastases. Int J Cancer 128(2): 352-360, 2011. PMID: 20715172. DOI: $10.1002 /$ ijc. 25591

21 Sasaki H, Yu CY, Dai M, Tam C, Loda M, Auclair D, Chen LB and Elias A: Elevated serum periostin levels in patients with bone metastases from breast but not lung cancer. Breast Cancer Res Treat 77(3): 245-252, 2003. PMID: 12602924. DOI: 10.1023/a:1021899904332

22 Wang Z and Ouyang G: Periostin: A bridge between cancer stem cells and their metastatic niche. Cell Stem Cell 10(2): 111-112, 2012. PMID: 22305559. DOI: 10.1016/j.stem.2012.01.002

23 Kudo Y, lizuka S, Yoshida M, Nguyen PT, Siriwardena SB, Tsunematsu T, Ohbayashi M, Ando T, Hatakeyama D, Shibata T, Koizumi K, Maeda M, Ishimaru N, Ogawa I and Takata T: Periostin directly and indirectly promotes tumor lymphangiogenesis of head and neck cancer. PLoS One 7(8): e44488, 2012. PMID: 22952986. DOI: 10.1371 /journal.pone.0044488

24 Lai $\mathrm{X}$ and Chen S: Identification of novel biomarker candidates for immunohistochemical diagnosis to distinguish low-grade chondrosarcoma from enchondroma. Proteomics 15(13): 23582368, 2015. PMID: 25755173. DOI: 10.1002/pmic.201400528.

25 Lu N, Lin T, Wang L, Qi M, Liu Z, Dong H, Zhang X, Zhai C, Wang Y, Liu L, Xiang L, Qi L, Han B and Li J: Association of sox 4 regulated by tumor suppressor mir-30a with poor prognosis in low-grade chondrosarcoma. Tumour Biol 36(5): 3843-3852, 2015. PMID: 25572678. DOI: 10.1007/s13277-014-3026-2

26 Zhang P, Li J, Song Y and Wang X: Mir-129-5p inhibits proliferation and invasion of chondrosarcoma cells by regulating sox4/wnt/beta-catenin signaling pathway. Cell Physiol Biochem 42(1): 242-253, 2017. PMID: 28535514. DOI: 10.1159/000477323

27 Shinohara N, Maeda S, Yahiro Y, Sakuma D, Matsuyama K, Imamura K, Kawamura I, Setoguchi T, Ishidou Y, Nagano S and Komiya S: Tgf-beta signalling and peg 10 are mutually exclusive and inhibitory in chondrosarcoma cells. Sci Rep 7(1): 13494, 2017. PMID: 29044189. DOI: 10.1038/s41598-017-13994-w

28 Vogelstein B, Papadopoulos N, Velculescu VE, Zhou S, Diaz LA Jr. and Kinzler KW: Cancer genome landscapes. Science 339(6127): 1546-1558, 2013. PMID: 23539594. DOI: 10.1126/science.1235122

29 Hatina J, Kripnerova M, Houfkova K, Pesta M, Kuncova J, Sana J, Slaby O and Rodriguez R: Sarcoma stem cell heterogeneity. Adv Exp Med Biol 1123: 95-118, 2019. PMID: 31016597. DOI: 10.1007/978-3-030-11096-3_7
30 Hogendoorn PC, Group EEW, Athanasou N, Bielack S, De Alava E, Dei Tos AP, Ferrari S, Gelderblom H, Grimer R, Hall KS, Hassan B, Hogendoorn PC, Jurgens H, Paulussen M, Rozeman L, Taminiau AH, Whelan J and Vanel D: Bone sarcomas: Esmo clinical practice guidelines for diagnosis, treatment and follow-up. Ann Oncol 21: v204-213, 2010. PMID: 20555083. DOI: $10.1093 /$ annonc/mdq223

31 Scully SP, Layfield LJ and Harrelson JM: Prognostic markers in chondrosarcoma: Evaluation of cell proliferation and of regulators of the cell cycle. Sarcoma 1(2): 79-87, 1997. PMID: 18521206. DOI: $10.1080 / 13577149778344$

32 Kudo A and Kii I: Periostin function in communication with extracellular matrices. J Cell Commun Signal 12(1): 301-308, 2018. PMID: 29086200. DOI: 10.1007/s12079-017-0422-6

33 Mosher DF, Johansson MW, Gillis ME and Annis DS: Periostin and TGF-beta-induced protein: Two peas in a pod? Crit Rev Biochem Mol Biol 50(5): 427-439, 2015. PMID: 26288337. DOI: $10.3109 / 10409238.2015 .1069791$

34 Loeser RF: Integrins and chondrocyte-matrix interactions in articular cartilage. Matrix Biol 39: 11-16, 2014. PMID: 25169886. DOI: $10.1016 /$ j.matbio.2014.08.007

35 Desgrosellier JS and Cheresh DA: Integrins in cancer: Biological implications and therapeutic opportunities. Nat Rev Cancer 10(1): 9-22, 2010. PMID: 20029421. DOI: 10.1038/nrc2748

36 Suresh A, Biswas A, Perumal S and Khurana S: Periostin and integrin signaling in stem cell regulation. Adv Exp Med Biol 1132: 163-176, 2019. PMID: 31037634. DOI: 10.1007/978-98113-6657-4_16

$37 \mathrm{Hu}$ WW, Chen PC, Chen JM, Wu YM, Liu PY, Lu CH, Lin YF, Tang $\mathrm{CH}$ and Chao CC: Periostin promotes epithelialmesenchymal transition via the mapk/mir-381 axis in lung cancer. Oncotarget 8(37): 62248-62260, 2017. PMID: 28977942. DOI: 10.18632/oncotarget.19273

38 Tang Y, Liu L, Wang P, Chen D, Wu Z and Tang C: Periostin promotes migration and osteogenic differentiation of human periodontal ligament mesenchymal stem cells via the jun aminoterminal kinases (jnk) pathway under inflammatory conditions. Cell Prolif 50(6): e12369, 2017. PMID: 28833827. DOI: 10.1111/cpr.12369

39 Kanno A, Satoh K, Masamune A, Hirota M, Kimura K, Umino J, Hamada S, Satoh A, Egawa S, Motoi F, Unno M and Shimosegawa T: Periostin, secreted from stromal cells, has biphasic effect on cell migration and correlates with the epithelial to mesenchymal transition of human pancreatic cancer cells. Int J Cancer 122(12): 2707-2718, 2008. PMID: 18381746. DOI: 10.1002/ijc.23332

40 Stacker SA, Williams SP, Karnezis T, Shayan R, Fox SB and Achen MG: Lymphangiogenesis and lymphatic vessel remodelling in cancer. Nat Rev Cancer 14(3): 159-172, 2014. PMID: 24561443. DOI: 10.1038/nrc3677

41 Takanami I, Abiko T and Koizumi S: Expression of periostin in patients with non-small cell lung cancer: Correlation with angiogenesis and lymphangiogenesis. Int J Biol Markers 23(3): 182-186, 2008. PMID: 18949745. DOI: 10.5301/jbm.2008.1999

Received June 19, 2020

Revised July 8, 2020

Accepted July 9, 2020 